\title{
Synthesis of a Fully Conjugated Phthalocyanine-Diketopyrrolopyrrole- Phthalocyanine Triad as Low Band Gap Donor in Small Molecule Bulk Heterojunction Solar Cells
}

\author{
Desiré Molina, ${ }^{[a]}$ Antonio Guerrero, ${ }^{[b]}$ Germà Garcia-Belmonte, ${ }^{* b]}$ Fernando Fernández-Lázaro ${ }^{[a]}$ \\ and Ángela Sastre-Santos ${ }^{*}[a]$
}

Keywords: Phthalocyanine / Diketopyrrolopyrrole / Organic Solar Cells/ Bulk heterojunction

\begin{abstract}
We describe the synthesis and photovoltaic properties of a fully conjugated phthalocyanine-diketopyrrolopyrrole-phthalocyanine triad (ZnPc-DPP-ZnPc), which presents strong visible absorption from 400 to $900 \mathrm{~nm}$. The synthesis of these phthalocyanine fully conjugated with diketopyrrolopyrrole provides access to a new family of low band gap materials $(1.57 \mathrm{eV})$.

Organic solar cells (OSCs) employing BHJ ZnPc-DPP$\mathrm{ZnPc}: \mathrm{PC}_{70} \mathrm{BM}$ films using $\mathrm{MoO}_{3}$ as anodic interfacial layer (IFL) show a power conversion efficiency of $1.04 \%$. The power conversion efficiency decreases considerably using as IFL PEDOT:PSS as a consequence of the protonation of the ZnPc.
\end{abstract}

\section{Introduction}

Although most commercial photovoltaic devices are made from silicon, organic solar cells (OSCs) are a promising alternative that can potentially provide light-weight, low-cost and flexibility advantages. ${ }^{1}$ Despite polymer-based donor materials are one of the most important components in organic bulk heterojunction (BHJ) as donors in the active layer, ${ }^{2}$ small molecule-based donor materials are an interesting alternative offering several promising advantages over their polymeric counterparts such as monodispersity and well-defined structure, easy purification, and better reproducibility (less batch-to-batch variation). ${ }^{3}$ Recently, single-molecule BHJ OSCs are approaching the results of conjugated polymers with power conversion efficiencies (PCEs) exceeding 7\%. ${ }^{4}$ However, this type of materials present other challenges such as generation of high quality films in which interconnectivity between the domains is adequate and the selection of the interfacial layer (IFL) is key to obtain optimum efficiencies.

On the other hand, devices based on both polymer and small molecule absorbers still miss a great part of the red and infrared region of the solar spectrum ultimately limiting their achievable efficiency. Indeed, to date examples in which contribution to the photocurrent takes place up to $900 \mathrm{~nm}$ (band gap $<1.6 \mathrm{eV}$ ) with driving force enough to provide efficient charge separation are rare. $^{2 \mathrm{~b}, 5}$

[a] División de Química Orgánica, Instituto de Bioingeniería, Universidad Miguel Hernández, Avda. de la Universidad, s/n, Elche 03202, Spain.

E-mail:*asastre@umh.es, garciag@fca.uji.es Homepage: URL of homepage

[b] Photovoltaic and Optoelectronic Devices Group, Departament de Física, Universitat Jaume I, ES, 12071 Castelló, Spain Supporting information for this article is available on the WWW under http://dx.doi.org/10.1002/ejoc.xxxxxxxxx.
Phthalocyanines (Pcs) and diketopyrrolopyrroles (DPPs) are two of the most extensively investigated molecules in organic photovoltaics because of their outstanding chemical and physical properties. Pcs are porphyrin analogues with, generally, planar structure and high conjugation of the central ring (18 $\pi$ electrons). They present interesting properties for application in photovoltaic cells, especially strong absorbance in the visible and near infrared radiation region and high thermal and chemical stabilities. ${ }^{6}$ Few examples are reported till now where soluble Pc derivatives are blended with acceptor materials to form BHJ active layers. ${ }^{7}$ Record efficiencies using Pcs up to $1.6 \%$ in solution-processed BHJs have been described by Torres and Bäuerle using RuPcs axially functionalized with pyridyl-dendritic oligothienylenes blended with [6,6]-phenyl-C71-butyric acid methyl ester $\left(\mathrm{PC}_{71} \mathrm{BM}\right){ }^{8}$

On the other hand, DPPs possess exceptional absorbance properties in the $500-600 \mathrm{~nm}$, strong fluorescent performance besides a great stability. A common feature of the DPP-based materials is their relatively high oxidation potential, leading to high-energy charge separated states when combined with fullerenes and correspondingly high voltages are obtained in solar cells. For these reasons DPPs, either as polymers or as single molecules, are being investigated as active layer on different OSCs devices. ${ }^{9}$ Nguyen and co-workers reported DPP-containing single-molecule donors that achieved up to $4.8 \%$ PCEs with $\mathrm{PC}_{70} \mathrm{BM}$ in solutionprocessed BHJ devices. ${ }^{10}$

The combination of the exceptional absorption characteristics of both Pcs and DPPs could provide highly light-absorbing single molecule donor materials in a broad visible-near infrared spectral region. Furthermore, in a molecule that combine two units of Pc covalently attached to the opposite positions of DPP unit, the strong donor character of the phthalocyanine will enhance the push-pull character of the molecule in a centrosymmetric configuration in order to increase intermolecular interaction and to reduce energetic disorder for charge transport. ${ }^{11}$

Here, we describe for the first time the synthesis of a strong light-harvester donor which presents strong visible absorption from 
400 to $900 \mathrm{~nm}$ ready to be used in small-molecule BHJ OSCs: a fully conjugated molecule that combines two planar aromatic zinc phthalocyanine units with the rigid $\pi$-conjugated DPP core, ZnPcDPP-ZnPc 1 (Chart 1). Moreover, we have also investigated the influence of the nature of the anodic IFL in the device performance using either PEDOT:PSS or $\mathrm{MoO}_{3}$ as IFL in solution processed BHJ devices.

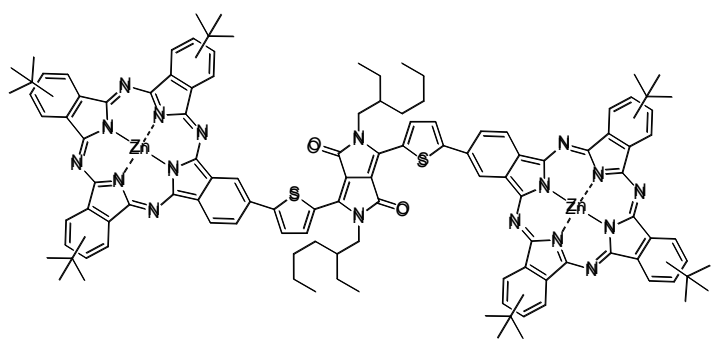

Chart 1. ZnPc-DPP-ZnPc 1

\section{Results and Discussion}

Synthesis. The synthesis of ZnPc-DPP-ZnPc 1 was carried out through two alternative pathways depicted in Scheme 1 (see SI for details). Route 1 involves a Suzuki cross coupling between DPPbisboronic ester $\mathbf{3}$ and zinc iodo-tri-tert-butylphthalocyaninate $\left[\mathrm{I}\left({ }^{\mathrm{B}} \mathrm{Bu}\right)_{3} \mathrm{ZnPc}, 4\right]$ in $65 \%$ yield. DPP 3 was synthesized from 2,5diethylhexyl-3,6-bisthiophen-2'-ylpyrrolo[3,4-c]pyrrole-1,4-dione $\left(\mathrm{T}_{2} \mathrm{DPP}\right)$ analogously as described in the literature. ${ }^{12}$ In the second approach (Route 2), ZnPc-DPP-ZnPc 1 was synthetized by statistical condensation of 4-tert-butylphthalonitrile and DPPbisphthalonitrile 2 in the presence of zinc acetate in 9\% yield. DPP-bisphthalonitrile 2 was synthesized in 81\% yield from DPPboronic ester 3 and 4-iodophthalonitrile via Suzuki reaction. Although the first pathway is a more convergent one giving rise to a higher global yield (24\% taking into consideration the $30 \%$ yield in the synthesis of ZnPc $\mathbf{4}^{13}$ ) of the ZnPc-DPP-ZnPc 1, the second one ( $7 \%$ global yield), the possibility to make statistical condensation of the DPP-bisphthalonitrile $\mathbf{2}$ with different substituted phthalonitriles paves the way to an unlimited variety of peripherally substituted phthalocyanines with different optoelectronic properties. ZnPc-DPP-ZnPc 1.

Characterization. As expected, ZnPc-DPP-ZnPc 1 is soluble in common organic solvents such as $\mathrm{CHCl}_{3}$, THF, toluene, and chlorobenzene. Broad signals were obtained for $\mathbf{1}$ in ${ }^{1} \mathrm{H}$-RMN even

using a coordinating solvent as THF- $\mathrm{d}_{8}$ due to the high $\pi-\pi$ stacking and also to the mixture of regioisomers.

The UV-vis spectra of the triad $\mathbf{1},\left({ }^{t} \mathrm{Bu}\right)_{4} \mathrm{ZnPc}$ and $\mathrm{T}_{2} \mathrm{DPP}$ in $\mathrm{CHCl}_{3}$ as solvent are represented in Figure 1a and their data included in Table S1. The existence of orbital overlap among the units in $\mathbf{1}$ leads to a strong interaction in the ground state, as reflected by the dramatic broadening and shift of the Q-band, wich reaches the near IR (Figure 1a). The UV-vis absorption spectrum of ZnPc-DPP-ZnPc 1 was also studied in different solvents, THF and $\mathrm{CHCl}_{3}$, and in solid state (Figure 1b) detecting important differences. The spectrum in THF shows a fine structure with maxima at $350 \mathrm{~nm}$ ( Soret band), 674 and $729 \mathrm{~nm}$ (Q1 and Q2 bands, attributed to the existence of regioisomers) and a shoulder at $605 \mathrm{~nm}$ (from the DPP unit). This well-resolved spectrum is a consequence of the coordination of the solvent (THF) to the $\mathrm{Zn}$ ions, thus preventing aggregation in the diluted solution. A more coarse and broad UV-vis spectrum with lower molar extinction coefficients is obtained in chloroform due to the $\pi-\pi$ aggregation effect, resulting in a high absorption from 500 to $900 \mathrm{~nm}$. The Soret band hardly moves two nanometers $(352 \mathrm{~nm})$ to the red, the shoulder appears at $617 \mathrm{~nm}$, the $\mathrm{Q}_{1}$ band undergoes a small bathochromic shift (from $674 \mathrm{~nm}$ in THF to $683 \mathrm{~nm}$ ), the $\mathrm{Q}_{2}$ band shifts to the blue $2 \mathrm{~nm}(727 \mathrm{~nm})$ and one additional band appears at $768 \mathrm{~nm}$. The broadest spectrum was obtained in solid state; the Q band has an amplitude of about $400 \mathrm{~nm}$ covering part of the near infrared till $1000 \mathrm{~nm}$.

(a)

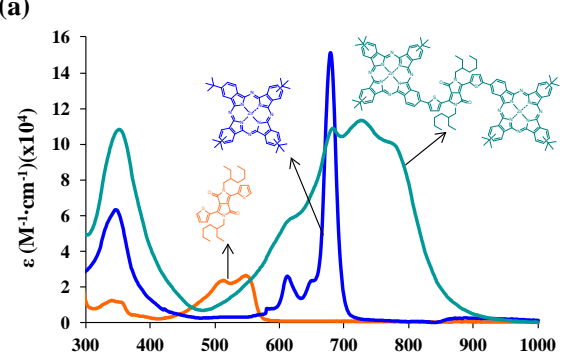

(b)

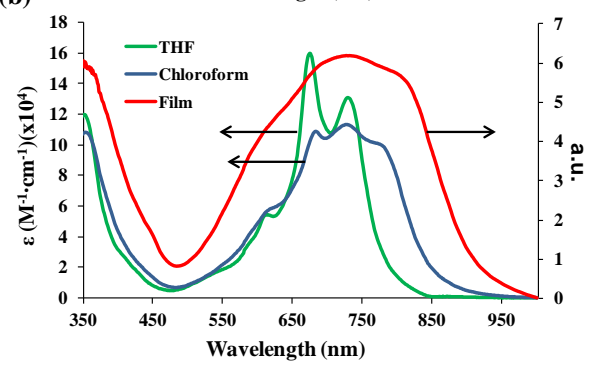

Figure 1. UV-vis spectra in $\mathrm{CHCl}_{3}$ as solvent of a) ZnPc-DPP-ZnPc $\mathbf{1}$ (turquoise line), $\mathrm{T}_{2} \mathrm{DPP}$ (orange line) and ( $\left.{ }^{\mathrm{B}} \mathrm{Bu}\right)_{4} \mathrm{ZnPc}$ (blue line), b) UV-vis spectra of ZnPc-DPP-ZnPc 1 in solid state (red line), $\mathrm{CHCl}_{3}$ (blue line) and THF (green line).

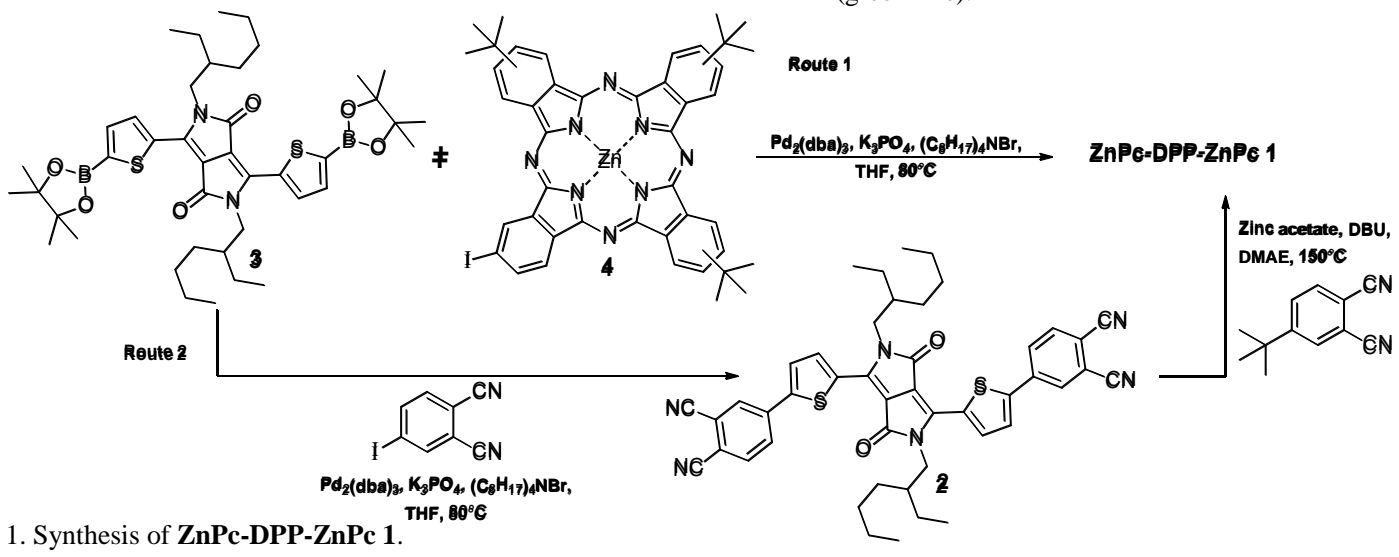

Scheme 1. Synthesis of ZnPc-DPP-ZnPc 1.

Submitted to the European Journal of Organic Chemistry 


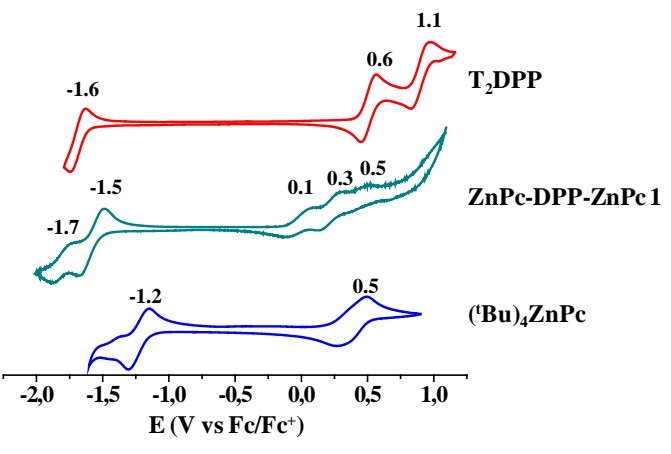

$\left({ }^{t} \mathrm{Bu}\right)_{4} \mathrm{ZnPc}$ revealed a fluorescence band located at $689 \mathrm{~nm}$ in $\mathrm{CHCl}_{3}$ solution (Fig. S6a). T2 $\mathrm{DPP}$ also shows a very high fluorescence in $\mathrm{CHCl}_{3}$ solution at 564 and $609 \mathrm{~nm}$ (Fig. S6b).

Figure 3. Cyclic voltammograms $\left(100 \mathrm{mV} \mathrm{s}^{-1}\right) \mathrm{vs} \mathrm{Fc} / \mathrm{Fc}^{+}$of $0.5 \mathrm{mM} \mathrm{ZnPc}-$ DPP-ZnPc 1 (turquoise line), and reference compounds, ( $\left.{ }^{t} \mathrm{Bu}\right)_{4} \mathrm{ZnPc}$ (blue line) and $\mathrm{T}_{2} \mathrm{DPP}$ (red line) in THF containing $0.10 \mathrm{M}$ of $\mathrm{Bu}_{4} \mathrm{NPF}_{6}$ as supporting electrolyte.

However, fluorescence is totally quenched in $\mathbf{1}$, which could be attributed to intramolecular energy and/or electron transfer processes from the ZnPc to the DPP moiety (Table S1).

Cyclic voltammetric studies performed on a THF solution of ZnPc-DPP-ZnPc 1 containing $0.1 \mathrm{M} \mathrm{Bu}_{4} \mathrm{NPF}_{6}$ as supporting electrolyte, showed three oxidation peaks at $0.1,0.3$ and $0.5 \mathrm{~V}$ and two reduction peaks at -1.5 and $-1.7 \mathrm{~V}$ vs $\mathrm{Fc} / \mathrm{Fc}^{+}$. The oxidation peaks are positively shifted comparing to the first oxidation of the $\left({ }^{t} \mathrm{Bu}\right)_{4} \mathrm{ZnPc}(0.5 \mathrm{~V})$ and the first and second oxidation peaks of the $\mathrm{T}_{2} \mathrm{DPP}$ reference compound $(0.6 \mathrm{~V}$ and $1.1 \mathrm{~V})$ revealing a strong coupling among all the moieties in the ground state. This coupling is also observed comparing the more negative shift of the reduction peaks of the triad with the first reduction potential of the $\left({ }^{t} \mathrm{Bu}\right)_{4} \mathrm{ZnPc}(-1.2 \mathrm{~V})$ and the first reduction potencial of the $\mathrm{T}_{2} \mathrm{DPP}$ $(-1.6 \mathrm{~V})$ (Figure 2 and Table S1).

The energies of the highest occupied molecular orbital (HOMO) and lowest unoccupied molecular orbital (LUMO) of ZnPc-DPPZnPc 1 have been determined to be approximately -4.90 and -3.33 $\mathrm{eV}$, respectively, calculated from the electrochemical oxidation and reduction potentials. The HOMO and LUMO energy values suggest that the frontier molecular orbitals line up favourably with those of common fullerene acceptors, as $\mathrm{PC}_{70} \mathrm{BM}$, which has HOMO and LUMO levels of -6.0 and $-4.0 \mathrm{eV}$, respectively, to generate useful $V_{\text {oc }}$ in BHJ solar cells (Table S1).

Solar Cell Performance. Photovoltaic devices were fabricated using the general architecture ITO/IFL/ZnPc-DPP-ZnPc 1:PC ${ }_{70} \mathrm{BM} / \mathrm{Ca} / \mathrm{Al}$ Poly(3,4-ethylenedioxythiophene):poly(styrenesulfonic acid) (PEDOT:PSS) was used as IFL anode. As it can be observed, there is a mismatch in the energy level alignment at the anode interface and an energy barrier to extract holes (see Figure S7). However, for preliminary results and considering there is no availability of HILs with adequate HOMO levels, we tested the material in this configuration. A series of studies were conducted to optimize the power conversion efficiencies (PCE).

The influence of the $\mathrm{ZnPc}-\mathrm{DPP}-\mathrm{ZnPc} 1: \mathrm{PC}_{70} \mathrm{BM}$ ratio was examined by looking at different compositions in chloroform. A detailed device fabrication process is described as supporting information. We found that a $1.5: 1$ ratio provided maximum efficiencies of $0.47 \%$ using PEDOT:PSS as IFL. For this combination, a photocurrent $\left(J_{\mathrm{sc}}\right)$ of $6 \mathrm{~mA} / \mathrm{cm}^{2}$ was obtained indicating that charge separation with the acceptor material occurs readily. Open circuit voltage $\left(V_{\text {oc }}\right)$ and fill factor $(F F)$ were low, seriously limiting the device performance. Considering that other families of small molecule donors are very sensitive to the selection of the anode IFL, we also examined the use of $\mathrm{MoO}_{3}$ as IFL. ${ }^{14}$ For this system, efficiencies could be doubled to obtain $1.04 \%$ with relatively high $V_{\text {oc }}$ for such a low band gap material and a short circuit current $\left(J_{\mathrm{sc}}\right)$ of $5.0 \mathrm{~mA} / \mathrm{cm}^{2}$. However, the $F F$ remains low (38\%). Typical current-voltage characteristics and external quantum efficiency (EQE) plots are shown in Figures 3 and the resulting photovoltaic parameters are summarized in Table 1. The EQE plot clearly shows that the contribution to the photocurrent extends up to $900 \mathrm{~nm}$.
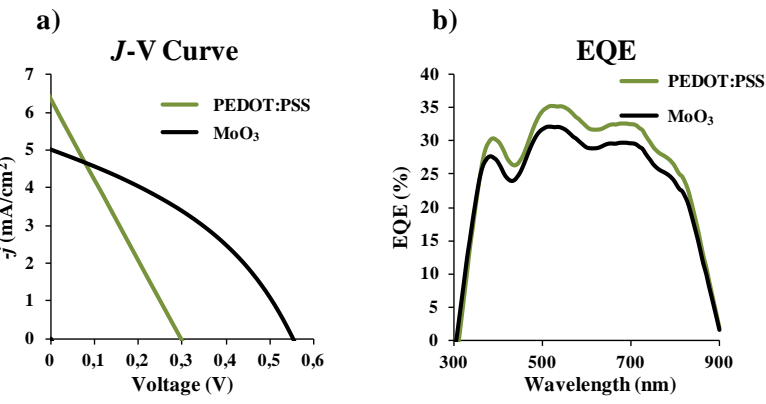

Figure 2. a) Current voltage characteristics of solar cells with an active layer comprised of ZnPc-DPP-ZnPc 1 and PC $_{70} \mathrm{BM}$; b) Corresponding external quantum efficiency plots (IFL is $\mathrm{MoO}_{3}$ )

Morphology measurements of ZnPc-DPP-ZnPC:PC ${ }_{70} \mathrm{BM}$ using chloroform as solvent have been evaluated by Atomic Force Microscopy (AFM) (See Fig S8). The film is smooth with RMS roughness of $1.7 \mathrm{~nm}^{2}$. Two different domains are visible, dark spots in a light matrix. It is possible that domains are not clearly interconnected indicating that the morphology is not optimum. However, AFM does provide information at the surface level and better interconnectivity could be possible in the bulk of the active layer. At this stage it appears that further material structural and device processing optimizations are needed. Nevertheless, these initial results are highly encouraging.

Table 1. Photovoltaic parameters.

\begin{tabular}{llllll}
\hline \multirow{2}{*}{ Entry } & Anode IFL & $\begin{array}{l}J_{\mathrm{sc}} \\
{[\mathrm{mA} / \mathrm{cm} 2]}\end{array}$ & $\begin{array}{l}V_{\mathrm{oc}} \\
{[\mathrm{mV}]}\end{array}$ & $\begin{array}{l}F F \\
{[\%]}\end{array}$ & $\begin{array}{l}\text { PCE } \\
{[\%]}\end{array}$ \\
\hline 1 & PEDOT:PSS & 6.36 & 296 & 25 & 0.47 \\
2 & $\mathrm{MoO}_{3}$ & 5.00 & 551 & 38 & 1.04 \\
\hline
\end{tabular}

Devices fabricated in the configuration glass/ITO/Anode IFL/ZnPc-DPPZnPc $1: \mathrm{PC}_{70} \mathrm{BM}$ (ratio 1.5:1)/Ca/Al.

To better understand the differences between the results obtained using PEDOT:PSS and $\mathrm{MoO}_{3}$ we studied the potential interface degradation of the active layer using PEDOT:PSS. It has previously been reported that PEDOT:PSS used as IFL can

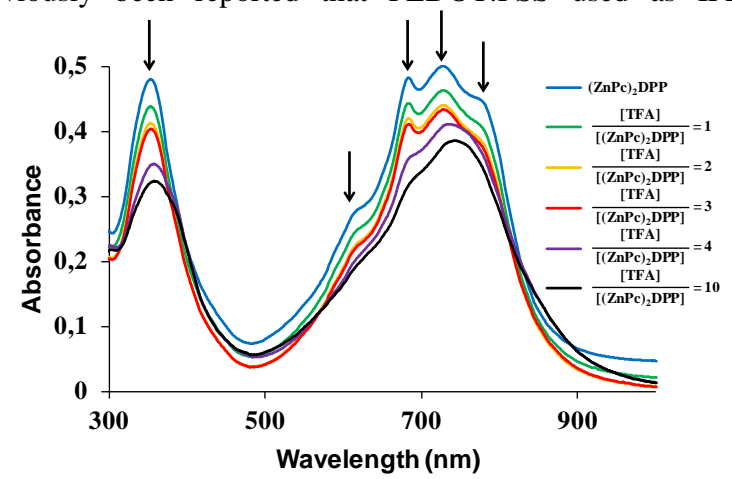

Figure 4. ZnPc-DPP-ZnPC 1 with different concentrations of trifluoroacetic acid (TFA) in chloroform. 
protonate basic nitrogens of the active layer materials which hinders the transfer of holes from the active layer to the anode. ${ }^{4 \mathrm{c}}$ In order to test this possibility for ZnPc-DPP-ZnPc 1, we measured the absorbance profile as a function of the concentration of trifluoroacetic acid and the resulting absorption profiles (Figure 4) showed significant changes immediately upon acid addition, namely new low energy transitions, confirming that the chromophore backbone is influenced by the protonation. This effect saturates when the TFA concentration is ten times greater than that of ZnPc-DPP-ZnPc 1. Therefore, the use of PEDOT:PSS is not recommended for future device optimization for materials with similar combination of structural moieties.

\section{Conclusions}

ZnPc-DPP-ZnPc 1 is the first example of a family of materials that present great potential to produce high efficiency BHJs due to its exceptional harvesting capability towards the near infrared and adequate electron donor character. When mixed with $\mathrm{PC}_{70} \mathrm{BM}$ and sandwiched between selective electrodes, efficiencies reached $1.04 \%$ when $\mathrm{MoO}_{3}$ is used as IFL. We have shown that the interaction with the anode IFL is critical, as for other small molecule absorbers, and needs to be taken into account for further development. Thus, the use of PEDOT:PSS leads to degradation of the active layer interface and the efficiency can be doubled with the use of $\mathrm{MoO}_{3}$.

The possibility to make statistical condensation of the DPPbisphthalonitrile 2 with different substituted phthalonitriles opens up a new way towards the synthesis of another family of efficient phthalocyanine molecules as sensitizers. Our future research will aim to find first different peripherically substituted phthalocyanines with a deeper HOMO level in order to get higher Voc and second optimum device architectures to take advantage of the benefits offered by this type of D-A single molecules.

\section{Acknowledgments}

We thank financial support from Spanish Ministry of Science and Innovation, Generalitat Valenciana and the European FEDER funds (CTQ2011-26455, Prometeo 2012/010, ACOMP/2012/, Prometeo/2009/058, ACOMP/2009/056, ACOMP/2009/095, and ISIC/2012/008 Institute of Nanotechnologies for Clean Energies). DM thanks Generalitat Valenciana for a VALi+d contract.

Received: ((will be filled in by the editorial staff)) Published online: ((will be filled in by the editorial staff) 
[1] For reviews, see: a) G. Dennler, M. C. Scharber, C. J. Brabec, Adv. Mater. 2009, 21, 1323-1338; b) P. M. Beaujuge, J. M. J. Fréchet, J. Am.Chem. Soc. 2011, 133, 20009-20029; c) G. Li, R. R. Zhu, Y. Yang, Nat. Photonics 2012, 6, 153-161; d) S. Günes, H. Neugebauer, N. S. Sariciftci, Chem. Rev. 2007, 107, 1324-1338; e) A. Facchetti, Chem. Mater. 2011, 23, 733-758; f) B. Walker, C. Kim, T.-Q Nguyen, Chem. Mater. 2011, 23,470-482; g) J. Roncali, Acc. Chem. Res., 2009, 42, 1719-1730.

[2] a) G. Yu, J. Gao, J. C. Hummelen, F. Wudl A. J. Heeger, Science 1995, 270, 1789-1791; b) L. Dou, J. You, J. Yang, C.-C. Chen, Y. He, S. Murase, T. Moriarty, K. Emery, G. Li, Y. Yang, Nat Photonics 2012, 6, 180-185; c) C. E. Small, S. Chen, J. Subbiah, C. M. Amb, S. W. Tsang, T. H. Lai, J. R. Reynolds, F. So, Nat. Photonics 2012, 6, 115-120; d) H.-Y. Chen, J. Hou, S. Zhang, Y. Liang, G. Yang, Y. Yang, L. Yu, Y. Wu, G. Li, Nat. Photonics 2009 3, 649-653; e) Y. J. Cheng, S. H. Yang, C. S. Hsu, Chem. Rev. 2009, 109, 5868-6923.

[3] a) M. T. Lloyd, J. E. Anthony, G. G. Malliaras, Mater. Today 2007, 11, 34-41; b) B. P. Rand, J. Genoe, P. Heremans, J. Poortmans, Progr. Photovolt.: Res. Appl. 2007, 15, 659-676.

[4] a) A. Mishra, P. Baüerle. Angew. Chem., Int. Ed. 2012, 51, 2020 2067; b) Y. Sun, G. C. Welch, W. L. Leong, C. J. Takacs, G. C. Bazan, A. J. Heeger, Nat. Mater. 2012, 11, 44-48; c) T. S. van der Poll, J. A. Love, T.-C. Nguyen, G. C. Bazan, Adv. Mater. 2012, 24 3646-3949; d) X. Liu, Y. Sun, L. A. Perez, W. Wen, M. F. Toney, A. J. Heeger, G. J. Bazan, J. Am. Chem. Soc. 2012, 134, 20609-20612; e) J. Zhou, X. Wan, Y. Liu, Y. Zuo, Z. Li, G. He, G. Long, W. Ni, C. Li, X. Su, Y. J. Chen, J. Am. Chem. Soc. 2012, 134, 16345-16351; f) A. Ko, K. Kyaw, D. H. Wang, V. Gupta, J. Zhang, S. Chand, G. C. Bazan, A. J. Heeger, Adv. Mat. 2013, 25, 2397-2402.

[5] J. You, L. Dou, K. Yoshimura, T. Kato, K. Ohya, T. Moriarty, K. Emery, C.-C. Chen, J. Gao, G. Li, Y. Yang, Nature Communications 2013, DOI: 10.1038/ncomms 2411.

[6] a) G. de la Torre, C. G. Claessens, T. Torres, Chem. Commun. 2007, 2000-2015; b) E. M. Barea, J. Ortiz, F. J. Payá, F. Fernández-Lázaro, F. Fabregat-Santiago, A. Sastre-Santos, J. Bisquert, Energy Environ. Sci. 2010, 3, 1985-1994.

[7] a) Q. Wang, Y. Li, X. Yan, M. Rathi, M. Ropp, D. Galipeau, J. Jiang, Appl. Phys. Lett. 2008, 93, 1; b) A. Varotto, C.-Y. Nam, I. Radivojevic, J. P. C. Tomé, J. A. S. Cavaleiro, C. T. Black, C. M. Drain, J. Am. Chem. Soc. 2010, 132, 2552-2554; c) A. Sánchez-Díaz, R. Pacios, U. Muñecas, T. Torres, E. Palomares, Org. Electron. 2011 12 , 329-335; d) O. O. Adegoke, M. Ince, A. Mishra, A. Green, O. Varnavski, M. V. Martínez-Díaz, P. Bäuerle, T. Torres, T. Goodson, J. Phys. Chem. C 2013, 117, 20912-20918.

[8] M. K. R. Fischer, I. Lopez-Duarte, M. M. Wienk, M. V. MartinezDiaz, R. A. J. Janssen, P. Bäuerle, T. Torres, J. Am. Chem. Soc. 2009 131, 8669-8676.

[9] a) S. Qu, H. Tian, Chem. Commun. 2012, 48, 3039-3051; b) D. Chandran, K.-S. Lee, Macromol. Res. 2013, 21, 272-283; c) P. P. Boix, M. M. Wienk, R. A. J. Janssen,.; G. Garcia-Belmonte, J. Phys. Chem. C 2011, 115, 15075-15080.

[10] B. Walker, A. B. Tamayo, X. Dang, P. Zalar, J. H. Seo, A. García, M. Tantiwiwat, T. Nguyen, Adv. Funct. Mater. 2009, 19, 3063-3069.

[11] a) R. Fitzner, E. Reinold, A. Mishra, E. Mena-Osteritz, H. Ziehlke, C. Körner, K. Leo, M. Riede, M. Weil, O. Tsaryova, A. Weiß, C. Uhrich, M. Pfeiffer, P. Bäuerle, Adv. Funct. Mater. 2011, 21, 897910; b) E. Lörtscher, ChemPhysChem 2011, 12, 2887-2889; c) E. J. Dell, B. Capozzi, K. H. DuBay, T. C. Berkelbach, J. R. Moreno, D. R. Reichman, L. Venkataraman, L. M. Campos, J. Am. Chem. Soc. 2013, 135, 11724-11727.

[12] a) H. Bürckstümmer, A. Weissenstein, D. Bialas, F. Würthner, J. Org. Chem. 2011, 76, 2426-2432; b) L. Huo, J. Hou, H.-Y. Chen, S Zhang, Y. Jiang, T. L. Chen, Y. Yang, Macromolecules 2009, 42, 6564-6571.

[13] E. M. Maya, P. Vázquez, T. Torres, Chem. Eur. J. 1999, 5, $2004-$ 2013.
[14] A. Guerrero, S. Loser, G. Garcia-Belmonte, C. J. Bruns, J. Smith, H. Miyauchi, S. I. Stupp, J. Bisquert, T. J. Marks, Phys. Chem. Chem. Phys. 2013, 15, 16456-16462. 
SYNTHESIS OF A FULLY CONJUGATED PHTHALOCYANINE-DIKETOPYRROLOPYRROLEPHTHALOCYANINE TRIAD AS LOW BAND GAP DONOR IN SMALL MOLECULE BULK HETEROJUNCTION SOLAR CELLS

Desiré Molina, ${ }^{\mathrm{a}}$ A. Guerrero, ${ }^{\mathrm{b}}$ G. García-Belmonte, ${ }^{* \mathrm{~b}}$ Fernando Fernández-Lázaro ${ }^{\mathrm{a}}$ and Ángela Sastre-Santos ${ }^{* a}$

(a) División de Química Orgánica Instituto de Bioingeniería, Universidad Miguel Hernández, Elche, Spain

(b) Grup de Dispositius Fotovoltaics i Optoelectrònics, Departament de Física. Universitat Jaume I, 12071, Castelló, Spain

* To whom correspondence should be addressed.

E-mail: asastre@umh.es 


\section{TABLE OFCONTENTS}

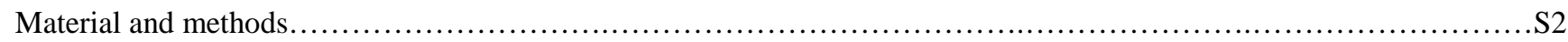

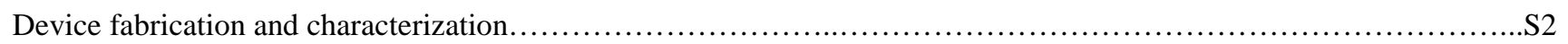

Synthesis of 2,5-bis(2-ethylhexyl)-3,6-bis[5-(zinc 6,16,23-tritert-butylphthalocyaninate-2-yl)thiophene-2-yl]-2,5-

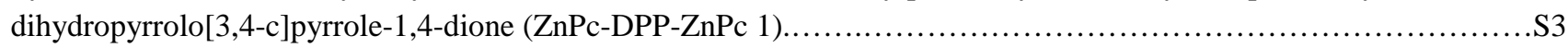

Synthesis of 2,5-bis(2-ethylhexyl)-3,6-bis[5-(1,2-dicyanobencene-4-yl)thiophene-2-yl]-2,5-dihydropyrrolo[3,4-c]pyrrole-1,4dione (2)...... S3

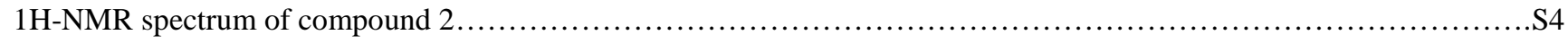

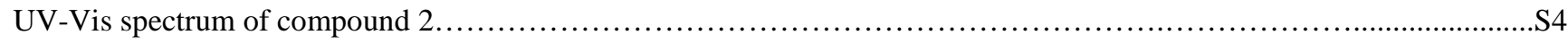

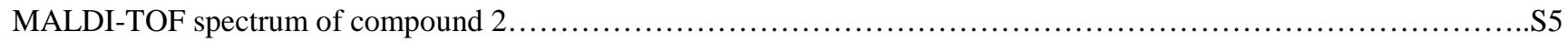

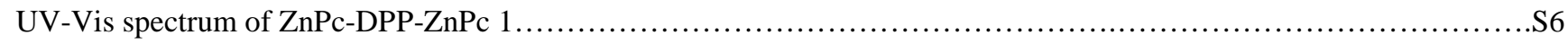

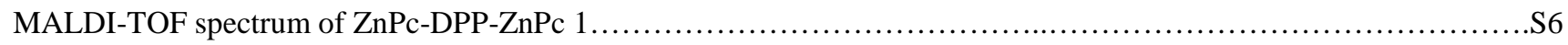

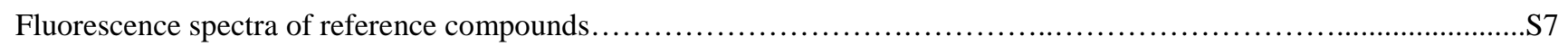

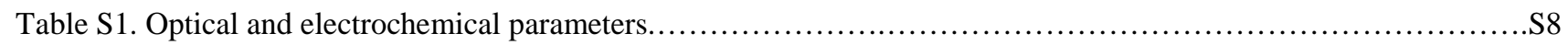

Energy level diagram of the devices. S¡Error! Marcador no 


\section{MATERIAL AND METHODS}

General methods. Solvents and reagents were obtained from commercial source and used as received. Column chromatography: SiO2 $(40-63 \mu \mathrm{m})$ TLC plates coated with SiO2 60F254 were visualized by UV light. NMR spectra were recorded at $25^{\circ} \mathrm{C}$ using a Bruker AC300 spectrometer. The solvents for spectroscopic studies were of spectroscopic grade and used as received. UV-vis spectra were measured with a Helios Gamma spectrophotometer. IR spectra were measured with Nicolet Impact 400D spectrophotometer. High resolution mass spectra were obtained from a Bruker Microflex LRF20 matrixassisted laser desorption/ionization time of flight (MALDI-TOF) using dithranol as matrix. Melting points were measured with Melting Point Apparatus SMP3.

\section{DEVICE FABRICATION AND CHARACTERIZATION}

\section{OPV DEVICE FABRICATION}

Patterned ITO-coated glass substrates with a resistivity of $10 \Omega / \mathrm{cm}^{2}$ and thickness were cleaned by sequential sonication at 50 ${ }^{\circ} \mathrm{C}$ in soap/DI water, DI water, methanol, isopropanol, and acetone for $30 \mathrm{~min}$. ITO substrates were then treated for $30 \mathrm{~min}$ in a UV/O3 oven (Jelight Co.). Next, either PEDOT:PSS or $\mathrm{MoO}_{3}$ was deposited. PEDOT:PSS (Clevios P VP Al 4083) was spun-cast at $5000 \mathrm{rpm}$ for $30 \mathrm{sec}$ and subsequently annealed at $150^{\circ} \mathrm{C}$ for $15 \mathrm{~min}$ in air. Samples were then transferred to a $\mathrm{N}_{2}$-filled glove box and an additional drying step was carried out at $100^{\circ} \mathrm{C}$ for $10 \mathrm{~min}$ to remove traces of water. $\mathrm{MoO}_{3}(\mathrm{Sig}-$ ma-Aldrich, 99.995\%) was thermally deposited at a pressure of $1.0 \times 10-6$ Torr at a rate of $0.1 \AA$ s. Prior to active layer deposition, the $\mathrm{MoO} 3$ films were transferred to air for $\sim 2 \mathrm{~min}$. Active layer solutions containing donor materials and $\mathrm{PC}_{71} \mathrm{BM}$ were formulated inside the glove box with optimum ratios (wt:wt): ZnPc-DPP-ZnPc 1:PC ${ }_{71} \mathrm{BM}$ (1.5:1.0 in chloroform; 7 $\mathrm{mg} / \mathrm{mL}$ ). Active layer solutions were stirred for $\sim 1 \mathrm{~h}$ at $45^{\circ} \mathrm{C}$. The active layer solution was spun-cast between $2000 \mathrm{rpm}$ for $1 \mathrm{~min}$ after passing the solution through a $0.22 \mu \mathrm{m}$ PTFE filter to afford active layers between $80 \mathrm{~nm}$. To finish device fabrication, Ca $(5.0 \mathrm{~nm}) / \mathrm{Ag}(100 \mathrm{~nm})$ were thermally evaporated, sequentially, at a base pressure of $\sim 1.0 \times 10-6$ Torr. The top $\mathrm{Ca} / \mathrm{Ag}$ electrodes were then encapsulated with UV-curable epoxy and a glass slide before testing. Each substrate had 4 cells with a defined average area of $0.25 \mathrm{~cm}^{2}$.

\section{DEVICE CHARACTERIZATION}

Current density-voltage measurements were carried out by illumination with a $1.5 \mathrm{G}$ illumination source $\left(1000 \mathrm{~W} \mathrm{~m}^{-2}\right)$ using an Abet Sun 2000 Solar Simulator. The light intensity was adjusted with a calibrated Si solar cell. UV/Vis data were obtained on films using a Cary 300 Bio Spectrophotometer. External Quantum Efficiency (EQE) measurements were performed using a $150 \mathrm{~W}$ Xe lamp coupled with a monochromator controlled by a computer. The light intensity was measured using an optical power meter 70310 from Oriel Instruments where a Si photodiode was used to calibrate the system. 
Synthesis of 2,5-bis(2-ethylhexyl)-3,6-bis[5-(zinc 6,16,23-tritert-butylphthalocyaninate-2-yl)thiophene-2-yl]-2,5dihydropyrrolo[3,4-c]pyrrole-1,4-dione (ZnPc-DPP-ZnPc 1).

Route 1: To a mixture of 2,5-bis(2-ethylhexyl)-3,6-bis[5-(4,4,5,5-tetramethyl-1,3,2-dioxoborolan-2-yl)thiophene-2-yl]-2,5dihydropyrrolo[3,4-c]pyrrole-1,4-dione (16 mg, $0.02 \mathrm{mmol}$ ), zinc 2-iodo-6,16,23-tri-tert-butylphthalocyaninate (50 mg, $0.06 \mathrm{mmol}), \mathrm{Pd}_{2}(\mathrm{dba})_{3}(0.6 \mathrm{mg}, 0.0007 \mathrm{mmol})$ and tetraoctylammonium bromide $(0.4 \mathrm{mg}, 0.0013 \mathrm{mmol})$ solved in $1 \mathrm{~mL}$ of THF was added a aqueous solution $0,1 \mathrm{M}$ of $\mathrm{K}_{3} \mathrm{PO}_{4}(0.0003 \mathrm{mg}, 0.07 \mathrm{mmol})$ under argon atmosphere and heated to $80^{\circ} \mathrm{C}$ overnight. The crude was purified by silica gel chromatography using chloroform/tetrahydrofuran 200:1 as eluent to obtain a turquoise solid (26 mg, 65\%).

Route 2: A mixture of 4-tert-butylphthalonitrile (107 mg, $0.58 \mathrm{mmol})$ and 2,5-bis(2-ethylhexyl)-3,6-bis[5-(1,2dicyanobencene-4-yl)thiophene-2-yl]-2,5-dihydropyrrolo[3,4-c]pyrrole-1,4-dione (25 $\mathrm{mg}, 0.032 \mathrm{mmol}$ ) and zinc acetate (23 $\mathrm{mg}, 0.128 \mathrm{mmol}$ ) was refluxed in dimethylaminoethanol (DMAE) $(2.5 \mathrm{~mL})$ under argon for $12 \mathrm{~h}$. The crude was washed and precipitated with methanol. The black solid obtained was purified by silica gel chromatography using chloroform/tetrahydrofuran 200:1 as eluent to obtain a turquoise solid (6 mg, 9\%).

m.p. $>300^{\circ} \mathrm{C}$. UV-vis $\left(\mathrm{CH}_{2} \mathrm{Cl}_{2}\right) \lambda_{\max / \mathrm{nm}}(\log \varepsilon)=346$ (5.05), 620 (4.85), 692 (5.04), 763 (5.02). HRMS (MALDI-TOF) $\mathrm{m} / \mathrm{z}$ : calculated for $\mathrm{C}_{118} \mathrm{H}_{116} \mathrm{~N}_{18} \mathrm{O}_{2} \mathrm{~S}_{2} \mathrm{Zn}_{2}\left(\mathrm{M}^{+}\right)$, 2008.755; found; 2088.782. FT-IR (KBr), $v\left(\mathrm{~cm}^{-1}\right)$ : 2953, 2921, 2856, 2195, 1664 (C=O lactam), 1608, 1548, 1486, 1444, 1393 (C-N), 1322, 1279, 1255.

\section{Synthesis of 2,5-bis(2-ethylhexyl)-3,6-bis[5-(1,2-dicyanobencene-4-yl)thiophene-2-yl]-2,5-dihydropyrrolo[3,4-} clpyrrole-1,4-dione (2).

A aqueous solution $0,1 \mathrm{M}$ of $\mathrm{K}_{3} \mathrm{PO}_{4}(61 \mathrm{mg}, 0.3 \mathrm{mmol})$ was added to a $5 \mathrm{~mL}$ THF solution of 2,5-bis(2-ethylhexyl)-3,6-bis[5(4,4,5,5-tetramethyl-1,3,2-dioxoborolan-2-yl)thiophene-2-yl]-2,5-dihydropyrrolo[3,4-c]pyrrole-1,4-dione (92 mg, 0.09 mmol), $\mathrm{Pd}_{2}(\mathrm{dba})_{3}$ (3 $\left.\mathrm{mg}, 0.003 \mathrm{mmol}\right)$, tetraoctylammonium bromide $(3 \mathrm{mg}, 0.005 \mathrm{mmol})$ and 4-iodophthalonitrile $(70 \mathrm{mg}$, $0.36 \mathrm{mmol}$ ) under argon atmosphere and the mixture was heated to $80^{\circ} \mathrm{C}$ overnight. The crude was purified by silica gel chromatography using chloroform/tetrahydrofuran 190:1 to obtain a metallic grey solid (58 $\mathrm{mg}, 81 \%)$.

m.p. $=287^{\circ} \mathrm{C} .{ }^{1} \mathrm{H}-\mathrm{NMR}\left(300 \mathrm{MHz}, \mathrm{THF}-\mathrm{d}_{8}\right): \delta=9.02(\mathrm{~d}, J=4,2 \mathrm{~Hz}, 2 \mathrm{H}), 8.43(\mathrm{~d}, J=1.9 \mathrm{~Hz}, 2 \mathrm{H}), 8.18\left(\mathrm{dd}, J_{1}=8.3 \mathrm{~Hz}, J_{2}=\right.$ $1.9 \mathrm{~Hz}, 2 \mathrm{H}), 8.03$ (d, $J=8.3 \mathrm{~Hz}, 2 \mathrm{H}), 7.95$ (d, $J=4.2 \mathrm{~Hz}, 2 \mathrm{H}), 4.12$ (m, 4H), 3.24 (s, 2H), $2.20(\mathrm{~s}, 4 \mathrm{H}), 2.11-1.86(\mathrm{~m}, 10 \mathrm{H})$, 1.69-1.47 (m, 14H). UV-vis $\left(\mathrm{CH}_{2} \mathrm{Cl}_{2}\right) \lambda_{\max / \mathrm{mm}}(\log \varepsilon)=368$ (4.50), 579 (4.59), 621 (4.59). HRMS (MALDI-TOF) $\mathrm{m} / \mathrm{z}$ : calculated for $\mathrm{C}_{46} \mathrm{H}_{44} \mathrm{~N}_{6} \mathrm{O}_{2} \mathrm{~S}_{2}\left(\mathrm{M}^{+}\right)$, 776.298; found 776.293. FT-IR (KBr), v $\left(\mathrm{cm}^{-1}\right)$ : $3093(\mathrm{C}-\mathrm{H}), 2952\left(\mathrm{CH}_{3}\right), 2919\left(\mathrm{CH}_{2}\right), 2849$ $\left(\mathrm{CH}_{2}\right), 2227(\mathrm{C} \equiv \mathrm{N}), 1735,1649(\mathrm{C}=\mathrm{O}$ lactam $), 1590,1488,1454,1408,1391$ (C-N lactam), 1235. 
1H-NMR SPECTRUM OF COMPOUND 2
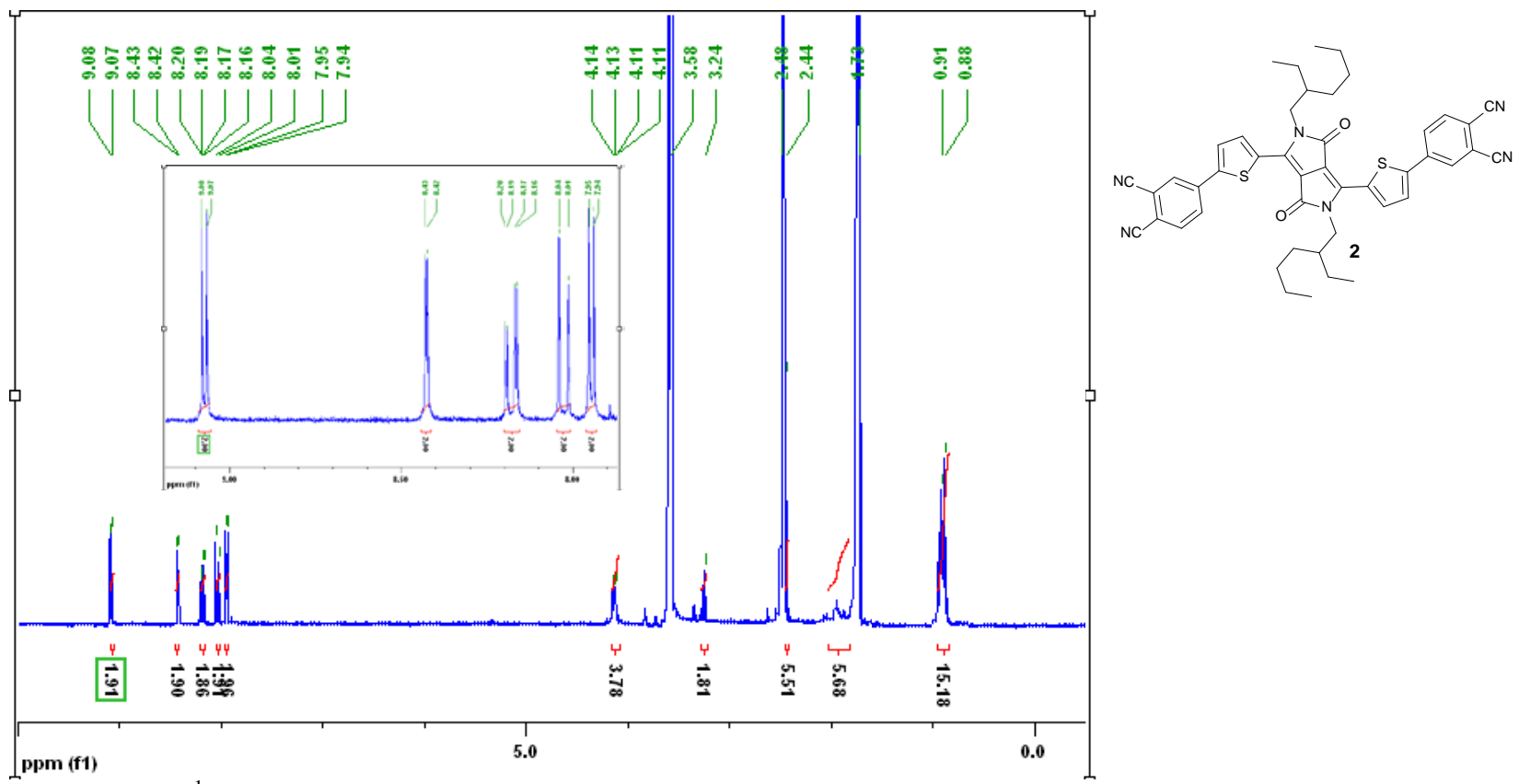

Figure S1. ${ }^{1} \mathrm{H}-\mathrm{RMN}\left(\mathrm{d}_{8}\right.$-THF) spectrum for 2,5-bis(2-ethylhexyl)-3,6-bis[5-(1,2-dicyanobencene-4-yl)thiophene-2-yl]-2,5dihydropyrrolo[3,4-c]pyrrole-1,4-dione (2)

\section{UV-VIS SPECTRA OF COMPOUND 2}

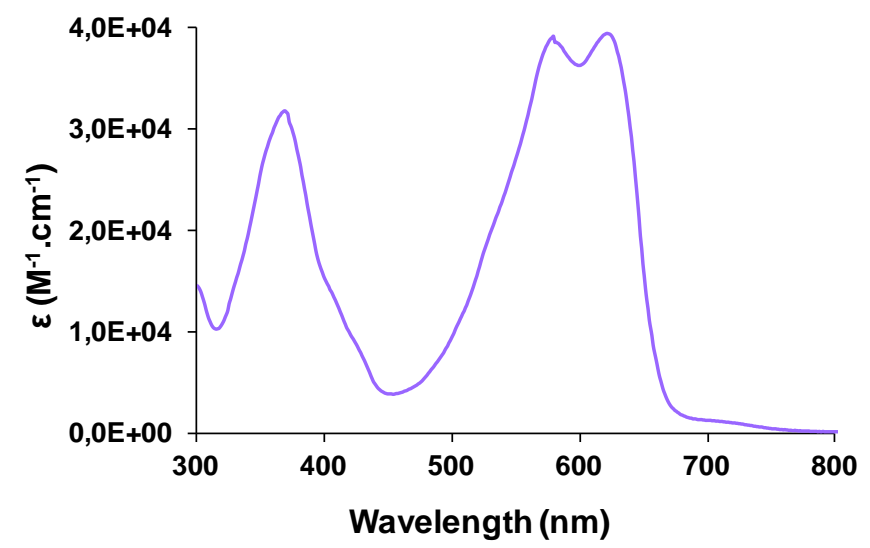

Figure S2. UV-vis absorption spectrum of $2\left(4 \cdot 10^{-6} \mathrm{M}\right)$ in dichlorometane as solvent. 
MALDI-TOF SPECTRUM OF COMPOUND 2
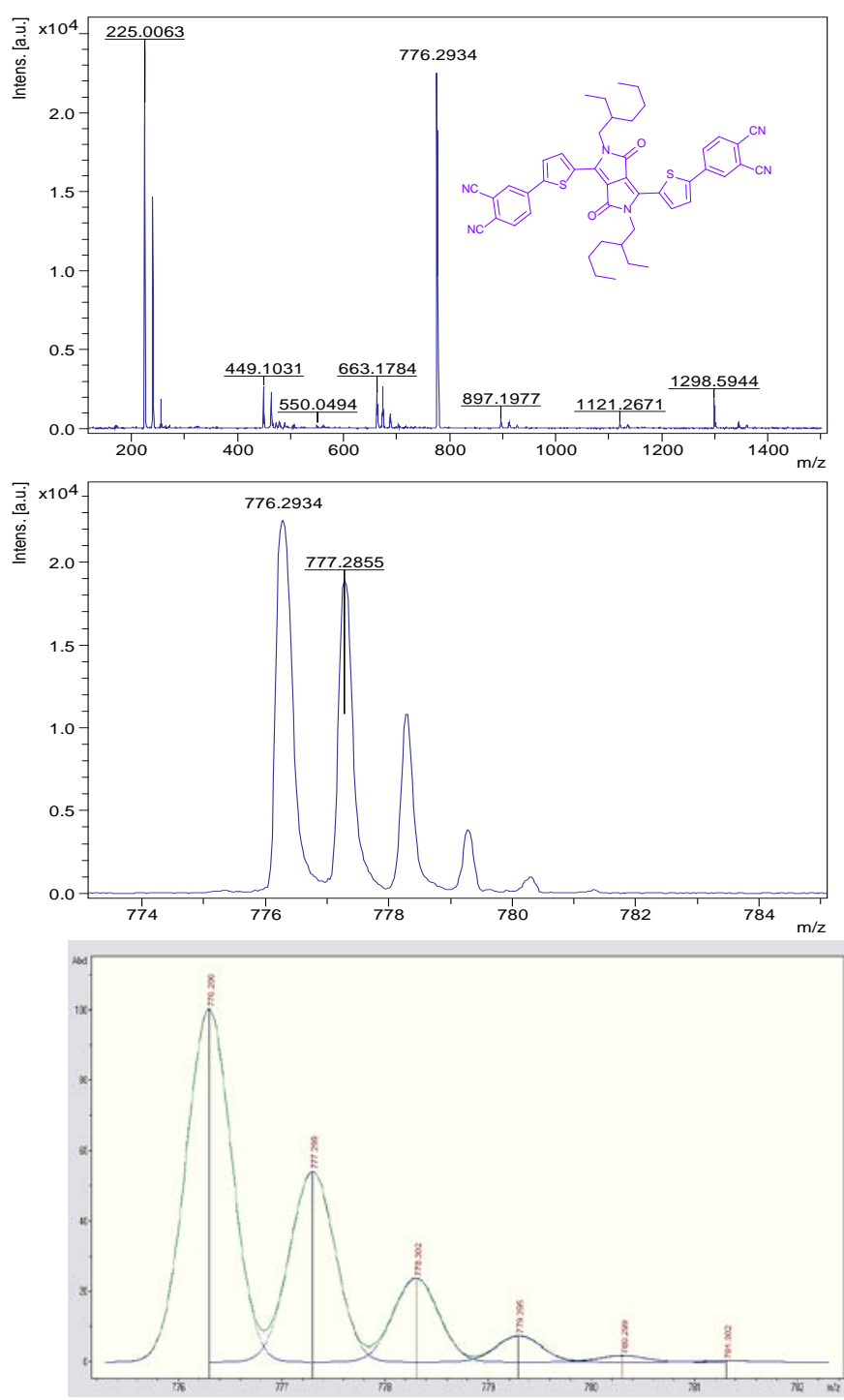

Figure S3. MALDI-TOF spectrum of compound 2. 
UV-VIS SPECTRA OF ZNPC-DPP-ZNPC 1

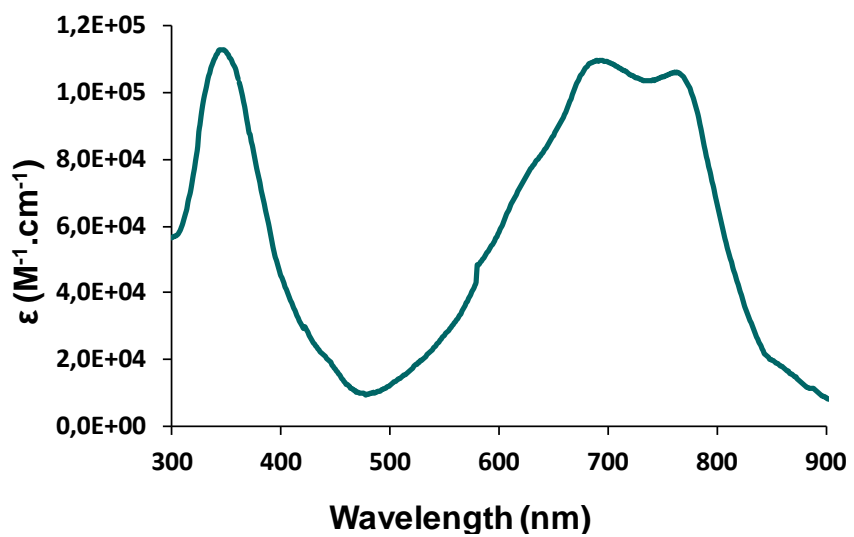

Figure S4. UV-vis absorption spectrum of ZnPc-DPP-ZnPc 1 in dichlorometane as solvent.

\section{MALDI-TOF SPECTRUM OF ZNPC-DPP-ZNPC 1}
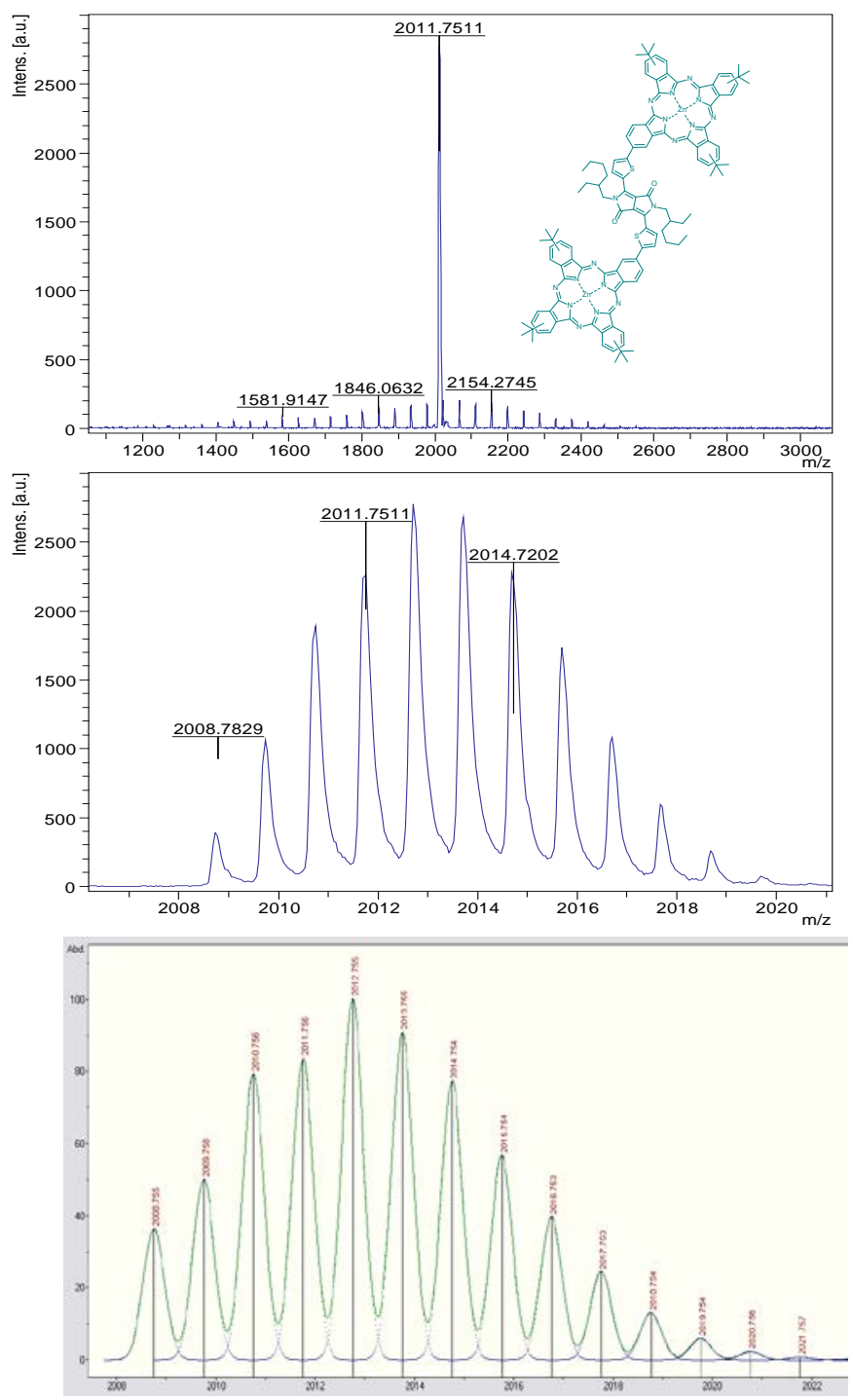

Figure S3. MALDI-TOF spectrum of ZnPc-DPP-ZnPc 1.

Submitted to the European Journal of Organic Chemistry 

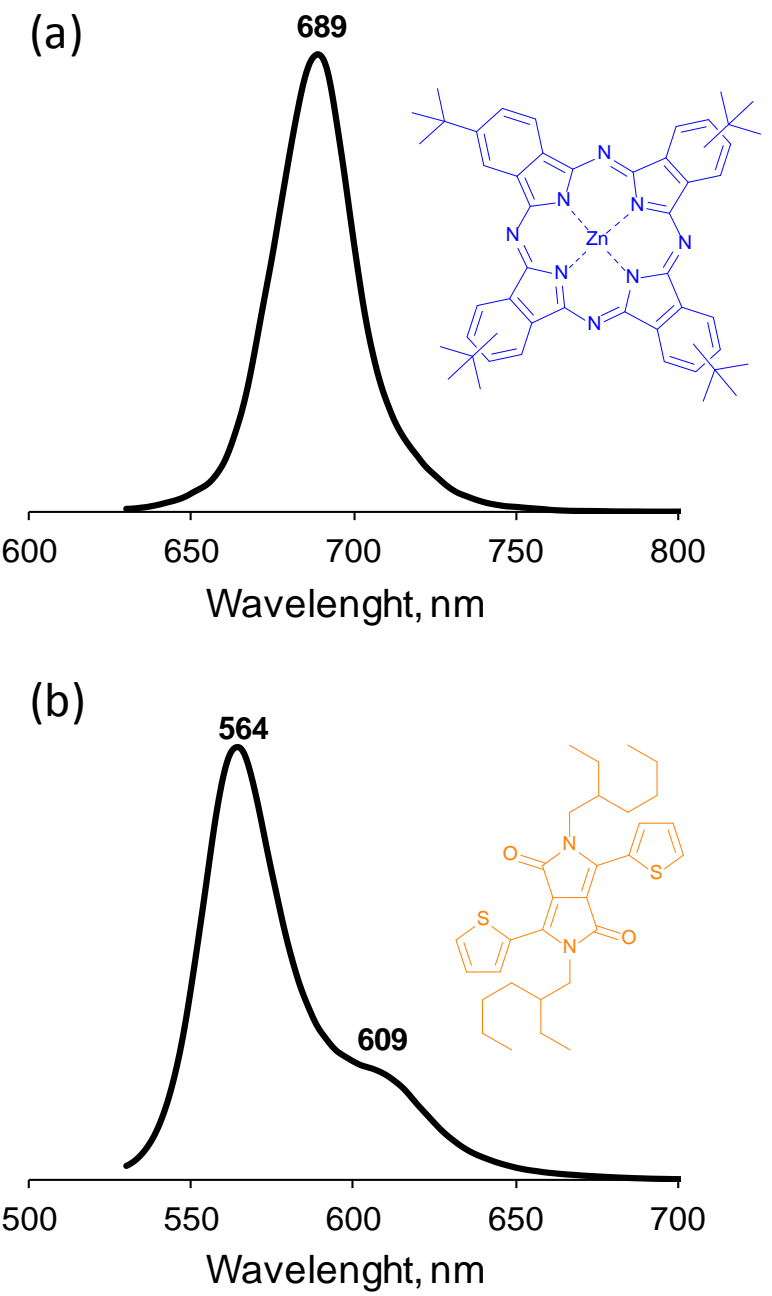

Figure S4. Fluorescence spectra of (a) $\left({ }^{t} \mathrm{Bu}\right)_{4} \mathrm{ZnPc}(\lambda \mathrm{ex}=612 \mathrm{~nm})$ and $(\mathrm{b}) \mathrm{T}_{2} \mathrm{DPP}(\square \mathrm{ex}=509 \mathrm{~nm})$ in deaerated chloroform at 298 K. No fluorescence emission from the ZnPc or DPP moiety of ZnPc-DPP-ZnPc 1 was observed. 
TABLE S1. OPTICAL AND ELECTROCHEMICAL PARAMETERS.

\begin{tabular}{|c|c|c|c|c|c|c|c|c|c|c|c|}
\hline Dye & $\begin{array}{l}\text { Absorbance } \\
\lambda \max (\mathrm{nm}) \mathrm{a}\end{array}$ & $\begin{array}{l}\text { Emission } \\
\lambda \max \\
(\mathrm{nm}) \mathrm{a}\end{array}$ & $E_{o x 1}^{b}$ & $\mathbf{E}_{\mathbf{0 x 2}}^{\mathbf{b}}$ & $\mathbf{E}_{\mathbf{0 x 3}}^{\mathbf{b}}$ & $E_{\text {red1 }}^{b}$ & $\mathbf{E}_{\text {red2 }}^{\mathbf{b}}$ & $\mathbf{E}_{\mathrm{g}}^{\mathbf{o p t}} \mathrm{C}$ & $\mathbf{E}_{\mathrm{g}}^{\mathrm{CV}} \mathrm{d}$ & HOMOe & LUMOf \\
\hline $\mathrm{T}_{2} \mathrm{DPP}$ & 548 & $564^{1}$ & 0.6 & 1.1 & 0.5 & -1.6 & --- & 2.23 & 2.22 & -5.34 & -3.12 \\
\hline ZnPc-DPP-ZnPc 1 & 694 & --- & 0.1 & 0.3 & --- & -1.5 & 1.7 & --- & 1.60 & -4.90 & -3.33 \\
\hline$\left({ }^{t} \mathrm{Bu}\right)_{4} \mathrm{ZnPc}$ & 679 & $689^{2}$ & 0.5 & --- & --- & -1.2 & --- & 1.82 & 1.70 & -5.42 & -3.60 \\
\hline
\end{tabular}

${ }^{a}$ Adsorption and emission spectra were measured in chloroform. ${ }^{\mathrm{b}}$ Redox potentials were measured THF with $0.1 \mathrm{M}$ $\mathrm{Bu}_{4} \mathrm{NPF}_{6}$ vs. $\mathrm{Fc} / \mathrm{Fc}^{+}$, with Pt counter electrode. ${ }^{\mathrm{c}} E_{g}^{\text {opt }}(\mathrm{eV})$ was determined from intersection of normaliced absorption and emission spectra registered in chloroform. ${ }^{\mathrm{d}} E_{g}^{C V}(\mathrm{eV})$ was calculated by $E_{g}^{C V}=E_{\text {red } 1}-E_{\text {ox } 1}$. ${ }^{\mathrm{e}} \mathrm{HOMO}$ (eV) was calculated by $\mathrm{HOMO}=-E_{\text {ox } 1}\left(\right.$ vs. $\left.\mathrm{Fc} / \mathrm{Fc}^{+}\right)-4.8 .{ }^{\mathrm{f}} \mathrm{LUMO}(\mathrm{eV})$ was calculated by LUMO $=\mathrm{HOMO}+E_{g}(\mathrm{eV})\left(\mathrm{CV}\right.$ or Opt). ${ }^{1}$ Excitation wavelength $\left(\lambda_{\text {exc }}\right)$ was $530 \mathrm{~nm} .{ }^{2} \lambda_{\text {exc }}=630 \mathrm{~nm}$.

\section{ENERGY LEVEL DIAGRAM OF THE DEVICES}

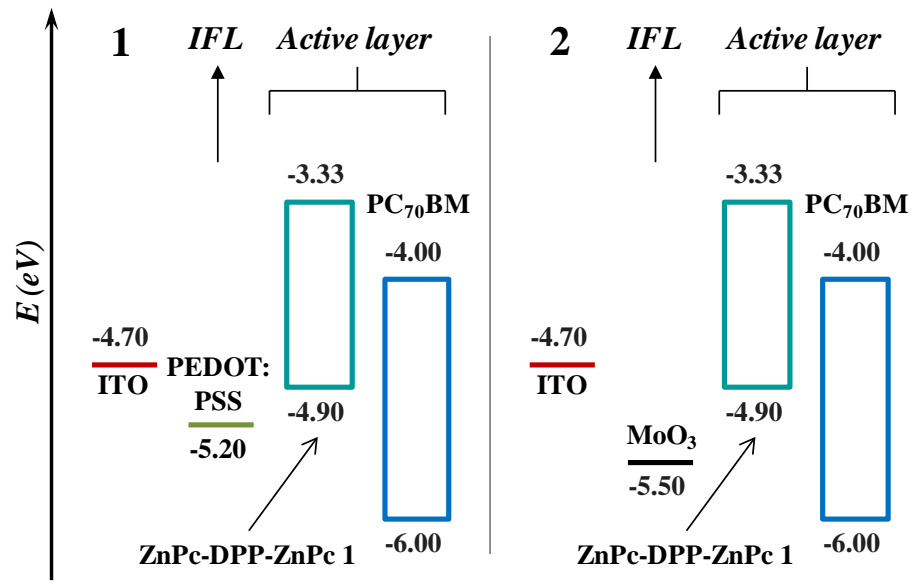

Figure S7. Energy level diagram showing the materials studied in this work, 1) IFL is PEDOT:PSS and 2) IFL is $\mathrm{MoO}_{3}$. 


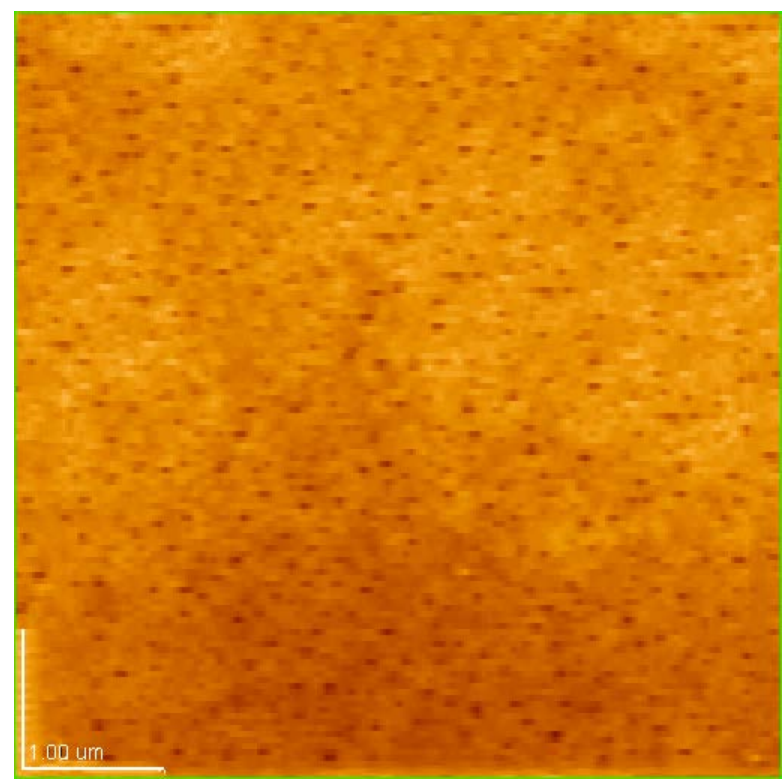

Fig S8: Tapping mode height AFM image of the active layer ZnPc-DPP-ZnPC:PC $70 \mathrm{BM}$ in chloroform as solvent. The RMS roughness is $1.7 \mathrm{~nm}^{2}$. 